\title{
Meta-analysis of minimally invasive internal thoracic artery bypass versus percutaneous revascularisation for isolated lesions of the left anterior descending artery
}

\author{
Omer Aziz, clinical research fellow, ${ }^{1}$ Christopher Rao, research fellow, ${ }^{1}$ Sukhmeet Singh Panesar, research \\ fellow, ${ }^{1}$ Catherine Jones, research fellow, ${ }^{1}$ Stephen Morris, senior lecturer, ${ }^{2}$ Ara Darzi, professor of \\ surgery, ${ }^{1}$ Thanos Athanasiou, consultant cardiac surgeon ${ }^{1}$
}

\begin{abstract}
'Department of Biosurgery and
Surgical Technology, Imperial

College London, St Mary's Hospital, London W2 1 NY

${ }^{2}$ Tanaka Business School, Imperial College London
\end{abstract}

Correspondence to: T Athanasiou tathan5253@aol.com

doi: 10.1136/bmj.39106.476215.BE

\section{ABSTRACT}

Objective To compare outcomes between minimally invasive left internal thoracic artery bypass and percutaneous coronary artery stenting as primary interventions for isolated lesions of the left anterior descending artery.

Design Meta-analysis of randomised and nonrandomised comparative peer reviewed publications. Data sources Embase, Medline, Cochrane, Google Scholar, and Health Technology Assessment databases (1966-2005).

Review methods Studies comparing the two procedures as the primary intervention for isolated left anterior descending artery stenosis were identified and the following extracted: study design, population characteristics, severity of coronary artery disease, cardiovascular risk factors, and outcomes of interest. Results 12 studies (1952 patients) reporting results from eight groups were included: one was a retrospective design, one prospective non-randomised, and six prospective randomised. Meta-analysis of randomised trials showed a higher rate of recurrence of angina (odds ratio $2.62,95 \%$ confidence interval 1.32 to 5.21 ), incidence of major adverse coronary and cerebral events (2.86, 1.62 to 5.08$)$, and need for repeat

revascularisation $(4.63,2.52$ to 8.51 ) with percutaneous stenting. No significant difference was found in myocardial infarction, stroke, or mortality at maximum follow-up between interventions.

Conclusions Minimally invasive left internal thoracic artery bypass for isolated lesions of the left anterior descending artery resulted in fewer complications in the mid-term compared with percutaneous transluminal coronary artery stenting.

\section{INTRODUCTION}

The incidence of coronary disease involving the left anterior descending artery has been reported as high as 50\% among patients undergoing coronary artery bypass grafting. ${ }^{1}$ The importance of this vessel (thought to be responsible for at least 50\% of the blood supply required for normal left ventricular function) is highlighted by the fact that high grade stenosis of the left anterior descending artery is associated with a worse prognosis than lesions in other coronary arteries. ${ }^{1}$ Two approaches are used for revascularisation in patients with occlusive coronary disease - transluminal, such as in percutaneous transluminal coronary artery stenting, and surgical bypass, such as in coronary artery bypass grafting. Although the transluminal approach is considered less invasive, with a reduced procedural morbidity, surgical bypass is thought to result in a more definitive revascularisation and improved long term survival. ${ }^{2}$ The ideal primary intervention for isolated lesions of the left anterior descending artery should therefore be one with reduced risk of restenosis while minimising procedural morbidity, mortality, and cost. ${ }^{34}$

Although percutaneous revascularisation carries a lower procedural morbidity, recent developments in minimally invasive direct coronary artery bypass have meant that definitive surgical revascularisation with left internal thoracic artery to left anterior descending artery anastomosis is possible through either a small left anterior thoracotomy or a ministernotomy, ${ }^{56}$ in most cases "off-pump" using cardiac stabilisation devices. This potentially removes the need for full sternotomy and cardiopulmonary bypass, both of which increase the cost, invasiveness, and morbidity of the bypass. Recent evidence suggests that for multiple vessel disease, coronary artery bypass grafting results in a more favourable outcome for cost, cardiac events, and the need for revascularisation. ${ }^{7}$ Much debate, however, centres on what primary revascularisation strategy is best suited to patients with isolated lesions of the left anterior descending artery, which is associated with different population characteristics. A recent meta-analysis comparing surgical bypass with percutaneous revascularisation of these lesions found in favour of surgery for cardiac events, mortality, and recurrence of angina, ${ }^{8}$ although significant heterogeneity existed because of the inclusion of both angioplasty (percutaneous transluminal coronary angioplasty) and stenting (percutaneous transluminal coronary artery stenting) in the percutaneous group and both coronary 
artery bypass grafting and minimally invasive direct coronary artery bypass in the surgery group. We carried out a meta-analysis to compare the outcomes from the best percutaneous intervention (transluminal coronary artery stenting) with the least invasive surgical intervention (minimally invasive direct coronary artery bypass with left internal thoracic artery) for the management of isolated lesions of the left anterior descending artery.

\section{METHODS}

We carried out a literature search using Embase, Medline, Cochrane Library, Google Scholar, and Health Technology Assessment databases, on all studies published between 1966 and 2006 reporting on minimally invasive direct coronary artery bypass with left internal thoracic artery anastomosis compared with percutaneous transluminal coronary artery stenting. We used the Mesh search headings "left internal thoracic artery", "MIDCAB", "stents", "coronary artery bypass/methods", "angioplasty, transluminal, percutaneous", and "comparative study". To broaden the search we used the "related articles" function. We reviewed all abstracts, studies, and citations irrespective of language.

Three reviewers (CR, SSP, and TA) independently extracted data from each study on first author, year of publication, population characteristics, design, followup, severity of coronary artery disease, cardiovascular risk factors, use of cardiopulmonary bypass, inclusion and exclusion criteria, and outcomes.

\section{Inclusion and exclusion criteria}

To be eligible for inclusion in our meta-analysis studies had to compare minimally invasive internal thoracic artery bypass with transluminal stenting for isolated lesions of the left anterior descending artery, include a patient group undergoing the procedure as a primary intervention, report on at least one outcome of interest, and contain a previously unreported patient group (if the same author published multiple studies reporting outcomes at different follow-up points, we extracted patient characteristics from the first study, with data for outcomes of interest at subsequent follow-up times extracted from the later studies). When two studies by the same institution reported the same outcomes at similar follow-up periods, we included in our analysis either the better quality or the most informative publication. We contacted the first author for clarification of discrepancies.

We excluded studies if the primary intervention strategy could not be defined and if the outcomes of interest were not reported or it was impossible to calculate these from the published results.

\section{Outcomes of interest and definitions}

Over the total follow-up period we compared the two interventions for several outcomes: recurrence of angina, postoperative myocardial infarction (both $Q$ and non-Q wave myocardial infarction within 30 days of operation), myocardial infarction at maximum follow-up (both $Q$ and non-Q wave myocardial infarction occurring at the maximum followup period for the study), stroke (including cerebrovascular event and transient ischaemic attacks), mortality (death at maximum follow-up), need for repeat revascularisation at maximum follow-up (defined as the need for percutaneous intervention or for bypass over the maximum follow-up period of the study), and major adverse coronary and cerebral events (a commonly reported composite outcome in cardiac revascularisation trials including myocardial infarction, stroke, and death).

In our study minimally invasive internal thoracic artery bypass refers to one of three types of bypass. The first is through a small left anterior thoracotomy, when the ribs are retracted to harvest the left internal thoracic artery (conventional technique). The second is when the artery is harvested robotically through a small left anterior thoracotomy without rib retraction (atraumatic coronary artery bypass). The third is through a mini-sternotomy.

\section{Statistical analysis}

We carried out our meta-analysis in line with Cochrane Collaboration recommendations and quality of reporting of meta-analyses guidelines. ${ }^{910}$ For categorical variables we used the odds ratio as the summary statistic. This ratio represents the odds of an adverse event occurring in the treatment (minimally invasive internal thoracic artery bypass) compared with control (transluminal stenting) group. An odds ratio of less than one favours the control group, and the point estimate of the odds ratio is considered statistically significant at the $\mathrm{P}=0.05$ level if the $95 \%$ confidence interval does not include the value 1 . To translate these results into benefits to clinical outcome we calculated the risk difference and number needed to treat. Risk difference (or absolute risk reduction) here is the difference in the incidence of postoperative complications between treatment and control groups. Number needed to treat is the number of patients who must be treated (using minimally invasive internal thoracic artery bypass) to prevent one complication event (NNT=1/risk difference).

We used the Mantel-Haenszel method to combine the odds ratio for the outcomes of interest. For those studies that contained a zero in one cell for the number of events of interest in one of the two groups we used Yates' correction. ${ }^{1112}$ These cells create problems with the computation of ratio measures and standard errors of treatment effects. We resolved this by adding the value 0.5 in each cell of the $2 \times 2$ table for the study in question. We excluded studies with no events in either group.

In this study we used a random effects model, where it is assumed that there is variation between studies and the calculated odds ratio thus has a more conservative value. ${ }^{1314}$ In surgical research, meta-analysis using this model is preferred, particularly because patients undergoing surgery in different centres have varying risk profiles and selection criteria for each surgical 
technique. In the primary analysis we considered only randomised trials (highest quality evidence). Analysis was carried out by using Intercooled Stata version 7.0 for Windows, RevMan version 4.2, and SPSS Sample Power 2.0 for power analysis calculations.

We used three strategies to assess heterogeneity. Firstly, we reanalysed data using both random and fixed effects models. Secondly, we evaluated publication bias using funnel plots. ${ }^{1315}$ Thirdly, we undertook a sensitivity analysis of three subgroups: randomised trials, studies with follow-up of 12 months or more, and studies with 70 or more patients in each group.

The overall incidence of need for revascularisation at maximum follow-up with transluminal stenting was $67 / 221$ (about 30\%). To rule out a 50\% relative risk reduction (from $30 \%$ to $15 \%$ ) with a $5 \%$ significance level and $90 \%$ power, we calculated that a traditional randomised controlled trial would require 174 patients in each arm.

\section{RESULTS}

Twelve studies published between 1966 and 2005 matched the inclusion criteria for comparing percutaneous transluminal coronary artery stenting with minimally invasive internal thoracic artery bypass for isolated lesions of the left anterior descending artery. These studies totalled 1952 patients; 67\% underwent transluminal stenting and 33\% underwent minimally invasive internal thoracic artery bypass. ${ }^{\text {w1-w15 }}$ Two groups each published three studies reporting on the same patient group but were included because they reported outcomes at different follow-up periods in each of these studies. ${ }^{\text {w2-w7 }}$ This paper therefore reports on the results of eight groups over the 12 studies. All three reviewers had $100 \%$ agreement on data extraction. The study designs were prospective randomised in six groups, ${ }^{\text {w1-w7 }}{ }^{\text {w13-w15 }}$ retrospective in one, ${ }^{\text {w11 }}$ and prospective non-randomised in one. ${ }^{\text {w9 }}$ Table 1 lists the characteristics of these studies. Figures 1 and 2 show the results from meta-analysis of the randomised trials.

\section{Outcomes of interest}

\section{Recurrence of angina}

Four groups reported on the recurrence of angina, all of which were randomised trials with a follow-up of at least 12 months. ${ }^{\text {w1-w7 w13 }}$ Meta-analysis of these studies showed a significantly higher incidence of recurrence at maximum follow-up with transluminal stenting (29\%) compared with minimally invasive internal thoracic artery bypass (14\%): odds ratio 2.62 (95\% confidence interval 1.32 to 5.21). The risk difference between transluminal stenting and minimally invasive internal thoracic artery bypass was $15 \%$ (4\% to $25 \%$; $\mathrm{NNT}=7$ ).

\section{Postoperative myocardial infarction}

Seven groups reported on postoperative myocardial infarction during the 30 days after either intervention, w2-w7 w9 w11 w13-w15 of which five were prospective randomised studies, ${ }^{\text {w2-w7 w13-w15 }}$ one retrospective, ${ }^{\text {w11 }}$ and one prospective non-randomised. ${ }^{\text {w9 }}$ Meta-analysis of the five randomised studies did not show any significant difference in the incidence of postoperative myocardial infarction between transluminal stenting $(3.7 \%)$ and minimally invasive internal thoracic artery bypass $(2.7 \%)$ : odds ratio $1.30(95 \%$ confidence interval 0.51 to 3.32 ). When all studies were considered, no significant difference was found in postoperative myocardial infarction between the groups $(1.3 \%$ with transluminal stenting $v \quad 1.7 \%$ with minimally invasive internal thoracic artery bypass: $0.91,0.38$ to 2.19$)$. Subgroup analysis of studies with a follow-up of at least 12 months ${ }^{\text {w2-w7 }}$ w9 w11 w13 w15 also did not show any significant difference between groups $(1.1 \%$ with transluminal stenting $v 1.5 \%$ with minimally invasive internal thoracic artery bypass; $0.91,0.29$ to 2.79 ).

\section{Myocardial infarction at maximum follow-up}

Seven groups reported on the incidence of myocardial infarction over the maximum follow-up period, which ranged from nine to 92 months. ${ }^{\text {w1-w4 w9 } 111 \text { w13-w15 }}$ Of these, five were randomised studies ${ }^{\mathrm{w1}-\mathrm{w} 4 \mathrm{w} 13-\mathrm{w} 15}$ and six contained groups that were followed up for at least a year. ${ }^{\text {w1-w4 w9 w11 w13 w15 }}$ Meta-analysis of the randomised trials showed no significant difference in the incidence of myocardial infarction between transluminal stenting $(2.4 \%)$ and minimally invasive internal thoracic artery bypass $(3.5 \%)$ : odds ratio 0.75 (95\% confidence interval 0.27 to 2.10$)$. When all studies were considered the incidence was $1.2 \%$ after transluminal stenting and $1.5 \%$ after minimally invasive internal thoracic artery bypass: 0.92 (0.36 to 2.34 ). When only studies with follow-up of at least one year were considered the incidence was $1.2 \%$ after transluminal stenting compared with $1.4 \%$ after minimally invasive internal thoracic artery bypass: 0.77 (0.25 to 2.36$)$.

\section{Stroke or transient ischaemic attack}

Five groups reported on the incidence of stroke (including transient ischaemic attack), ${ }^{\text {w2-w4 w9 w11 w13 w15 }}$ of which three were prospective randomised trials. ${ }^{\text {w2-w4 w13 w15 }}$ All studies had a follow-up time greater than 12 months. Meta-analysis of the randomised trials did not show a significant difference in the incidence of stroke between transluminal stenting $(1.9 \%)$ and minimally invasive internal thoracic artery bypass $(0.5 \%)$ : odds ratio $2.52(95 \%$ confidence interval 0.48 to 13.2 ). This was also true when all studies were considered $(2 \%$ with transluminal stenting $v$ $1.1 \%$ with minimally invasive internal thoracic artery bypass; $1.67,0.67$ to 4.19 ).

\section{Mortality at maximum follow-up}

Five groups reported on mortality at maximum followup after the two interventions ${ }^{\text {w1-w7 w11 w13 w15 }}$ of which four were randomised. ${ }^{\text {w1-w7 w15 }}$ Meta-analysis of the randomised studies did not show any significant difference in mortality at maximum follow-up between interventions (1.7\% with transluminal stenting $v 3.4 \%$ with minimally invasive internal thoracic artery bypass; odds ratio $0.63,95 \%$ confidence interval 0.16 
Table 1| Study and patient characteristics of studies included in meta-analysis

\begin{tabular}{|c|c|c|c|c|c|c|c|c|}
\hline Variable & $\begin{array}{l}\text { Cisowski } \\
\text { (2002)w6 w7 }\end{array}$ & $\begin{array}{l}\text { Drenth } \\
(2002) \text { w2 w3 }\end{array}$ & $\begin{array}{l}\text { Shirai } \\
(2004) w 9\end{array}$ & $\begin{array}{l}\text { lakovou } \\
\text { (2002)w11 }\end{array}$ & $\begin{array}{l}\text { Diegeler } \\
(2002) w 13\end{array}$ & $\begin{array}{l}\text { Reeves } \\
(2004) w 1\end{array}$ & $\begin{array}{l}\text { Hong } \\
(2005) w 14\end{array}$ & $\underset{(2005) w 15}{\operatorname{Kim}}$ \\
\hline Study design & $\begin{array}{l}\text { Prospective } \\
\text { randomised }\end{array}$ & $\begin{array}{l}\text { Prospective } \\
\text { randomised }\end{array}$ & $\begin{array}{c}\text { Prospective } \\
\text { non- } \\
\text { randomised }\end{array}$ & Retrospective & $\begin{array}{l}\text { Prospective } \\
\text { randomised }\end{array}$ & $\begin{array}{l}\text { Prospective } \\
\text { randomised }\end{array}$ & $\begin{array}{l}\text { Prospective } \\
\text { randomised }\end{array}$ & $\begin{array}{l}\text { Prospective } \\
\text { randomised }\end{array}$ \\
\hline Country & Poland & Netherlands & $\begin{array}{l}\text { United } \\
\text { States }\end{array}$ & United States & Germany & $\begin{array}{l}\text { United } \\
\text { Kingdom }\end{array}$ & South Korea & South Korea \\
\hline Duration of study (months) & 12 & 36 & 92 & 39 & 48 & 12 & 9 & 24 \\
\hline \multicolumn{9}{|l|}{ No of patients: } \\
\hline PTCS group & 50 & 51 & 429 & 441 & 110 & 50 & 119 & 50 \\
\hline MIDCAB group & 50 & 51 & 152 & 119 & 110 & 50 & 70 & 50 \\
\hline \multicolumn{9}{|l|}{ Mean (SD) age (years): } \\
\hline PTCS group & $53.3(10.2)$ & $61(1.3)$ & $63(11)$ & $63(12)$ & $62.5(10.2)$ & $54.5(49-61)^{\star}$ & $60.5(9.6)$ & $61(12)$ \\
\hline MIDCAB group & $54.1(9.1)$ & $60(1.6)$ & $61(12)$ & $62(12)$ & $61.6(10.0)$ & $\begin{array}{c}58.8(53-67) \\
\star\end{array}$ & $61.4(9.9)$ & $63(12)$ \\
\hline
\end{tabular}

Men (\%):

\begin{tabular}{lllllllll}
\hline PTCS group & 84 & 75 & 65 & 68 & 72 & 86 & 64 & 70 \\
\hline MIDCAB group & 82 & 78 & 73 & 71 & 77 & 64 & 70 \\
\hline Patients with diabetes (\%): & & & & & & & \\
\hline PTCS group & 8 & 18 & 24 & 22 & 34 & - & 37 & 20 \\
\hline MIDCAB group & 6 & 24 & 26 & 17 & 25 & - & 49 \\
\hline
\end{tabular}

Patients with hypertension

(\%):

\begin{tabular}{lllllllll} 
PTCS group & 52 & 33 & 53 & 54 & 72 & - & 50 & 55 \\
\hline MIDCAB group & 56 & 16 & 59 & 55 & 71 & 56 & \\
\hline Smokers (\%): & & & & & & & \\
\hline PTCS group & 52 & 30 & 19 & 46 & 25 & - & 40 \\
\hline MIDCAB group & 48 & 37 & 15 & 56 & 25 & - & 46
\end{tabular}

Previous myocardial

infarction (\%):

\begin{tabular}{|c|c|c|c|c|c|c|c|c|}
\hline PTCS group & - & 18 & 43 & 22 & 45 & - & 22 & 22 \\
\hline MIDCAB group & - & 24 & 37 & 22 & 45 & - & 23 & 22 \\
\hline \multicolumn{9}{|c|}{ Angina class $0-2 \dagger(\%)$ : } \\
\hline PTCS group & 52 & 27 & - & - & - & - & 53 & 24 \\
\hline MIDCAB group & 46 & 31 & - & - & - & - & 49 & 36 \\
\hline \multicolumn{9}{|c|}{ Unstable angina (\%): } \\
\hline PTCS group & 10 & - & - & 68 & - & - & 50 & 65 \\
\hline MIDCAB group & 8 & - & - & 60 & - & - & 43 & 55 \\
\hline \multicolumn{9}{|c|}{ Hypercholesterolaemia (\%): } \\
\hline PTCS group & 78 & 45 & 60 & 60 & 70 & - & 55 & 60 \\
\hline MIDCAB group & 76 & 41 & 62 & 72 & 73 & - & 51 & 70 \\
\hline
\end{tabular}

Previous cerebrovascular

event (\%):

\begin{tabular}{llllllll}
\hline PTCS group & - & - & 6.3 & 6.4 & - & - & 2.5 \\
\hline MIDCAB group & - & - & 4.2 & 6.8 & - & - & 2.9 \\
\hline
\end{tabular}

Family history of coronary

artery disease (\%):

\begin{tabular}{|c|c|c|c|c|c|c|c|c|}
\hline PTCS group & 40 & 50 & - & - & 18 & - & 9 & - \\
\hline \multicolumn{9}{|l|}{$\begin{array}{l}\text { Mean (SD) ejection fraction } \\
\%:\end{array}$} \\
\hline PTCS group & - & - & $51(11)$ & $52(12)$ & $62(15)$ & - & $52.8(8.8)$ & $51(11)$ \\
\hline MIDCAB group & - & - & $53(11)$ & $48(7)$ & $63(11)$ & - & $51.9(9.1)$ & 49 (13) \\
\hline Matching criteriał & $1,2,4-8$ & $1,2,4$ & $1,2,5$ & 8 & 1,2 & $1,2,4$ & 1 & $1,2,7$ \\
\hline
\end{tabular}

PTCS=percutaneous transluminal coronary artery stenting; MIDCAB=minimally invasive direct coronary artery bypass with left internal thoracic artery to left anterior descending artery anastomosis.

*Standard deviation (interquartile range).

†Canadian Cardiovascular Society criteria.

$\ddagger 1=$ isolated severe stenosis $(\geq 50 \%)$ in proximal left anterior descending artery; $2=$ agreement that equivalent revascularisation possible; $3=$ multivesse

disease; $4=$ severe angina; $5=$ artery diameter $\geq 3 \mathrm{~mm}$; $6=$ lesion length $\geq 20 \mathrm{~mm} ; 7=$ no other significant coronary lesions; $8=$ ejection fraction $40 \%-45 \%$. 


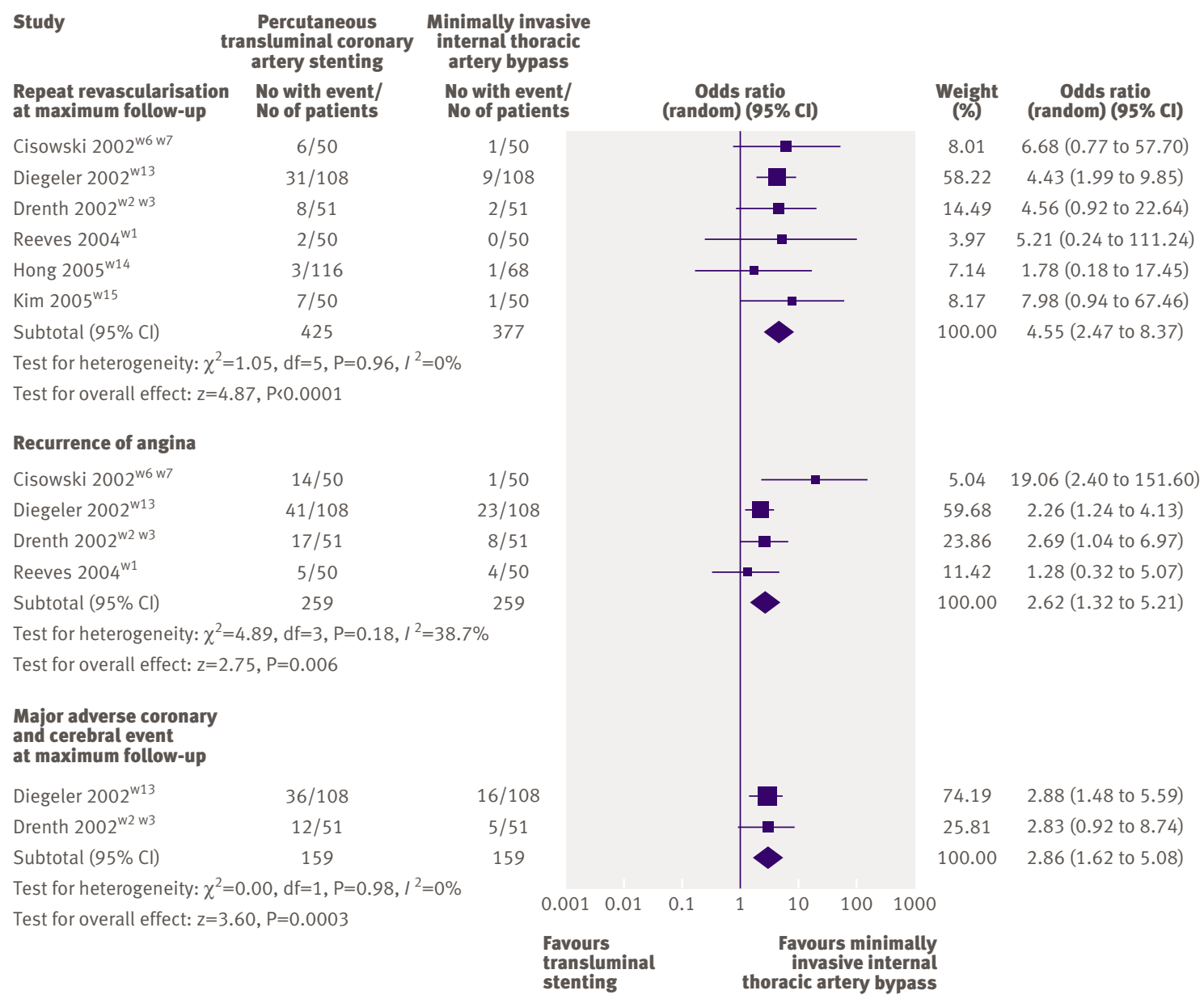

Fig 1 | Forest plot showing results from meta-analysis of randomised trials reporting need for repeat revascularisation at maximum follow-up, recurrence of angina, and major adverse coronary and cerebral event after minimally invasive thoracic artery bypass compared with transluminal stenting

to 2.4). When all studies were considered still no significant difference was found $(2.9 \%$ with transluminal stenting $v 3.4 \%$ with minimally invasive internal thoracic artery bypass; $0.83,0.35$ to 1.97 ).

\section{Need for repeat revascularisation at maximum follow-up}

Eight groups reported the need for repeat revascularisation (percutaneous or surgical bypass) over their maximum follow-up period. ${ }^{\text {w1-w7 }}$ w9w11 w13-w15 Metaanalysis of the six randomised trials ${ }^{\text {w1-w7 w13-w15 }}$ produced a revascularisation rate of $13 \%$ for transluminal stenting compared with $4 \%$ for minimally invasive internal thoracic artery bypass (odds ratio 4.63, 95\% confidence interval 2.52 to 8.51 ), significantly favouring surgery. The risk difference between transluminal stenting and minimally invasive internal thoracic artery bypass was $9 \%(2 \%$ to $17 \%$; NNT=11). When all studies were considered this difference was still statistically significant $(14.3 \%$ with transluminal stenting $v$ $4.4 \%$ with minimally invasive internal thoracic artery bypass; $3.56,2.35$ to 5.41 ). Subgroup analysis of seven studies with at least 12 months of follow-up also showed significantly higher revascularisation rates after transluminal stenting (15.4\%) compared with minimally invasive internal thoracic artery bypass
$(4.8 \%)$ revascularisation: $3.65,2.39$ to $5.59 .{ }^{\text {w1-w7 }}$ w9 w11 w13 w15

Composite outcome for major adverse coronary and cerebral events

Three studies reported the incidence of the composite outcome for major adverse coronary and cerebral events at maximum follow-up $\mathrm{p}^{\mathrm{w} 2-\mathrm{w} 4 \mathrm{w} 9 \mathrm{w} 13}$ of which two were randomised controlled trials. ${ }^{\text {w2-w4 w13 }}{ }^{\text {Meta-analy- }}$ sis of randomised trials showed a significantly higher incidence of major adverse coronary and cerebral events after transluminal stenting (30\%) compared with minimally invasive internal thoracic artery bypass (11\%) revascularisation (odds ratio 2.86, 95\% confidence interval 1.62 to 5.08). The risk difference between transluminal stenting and minimally invasive internal thoracic artery bypass was $19 \%$ (8\% to $25 \%$; $\mathrm{NNT}=5)$. When all studies were considered the results still favoured surgical revascularisation $(21.4 \%$ with transluminal stenting $v 11.1 \%$ with minimally invasive internal thoracic artery bypass; $2.62,1.71$ to 4.02 ).

\section{Sensitivity analysis}

Table 2 shows the results for sensitivity analysis using fixed and random effects models for postoperative myocardial infarction, need for repeat 


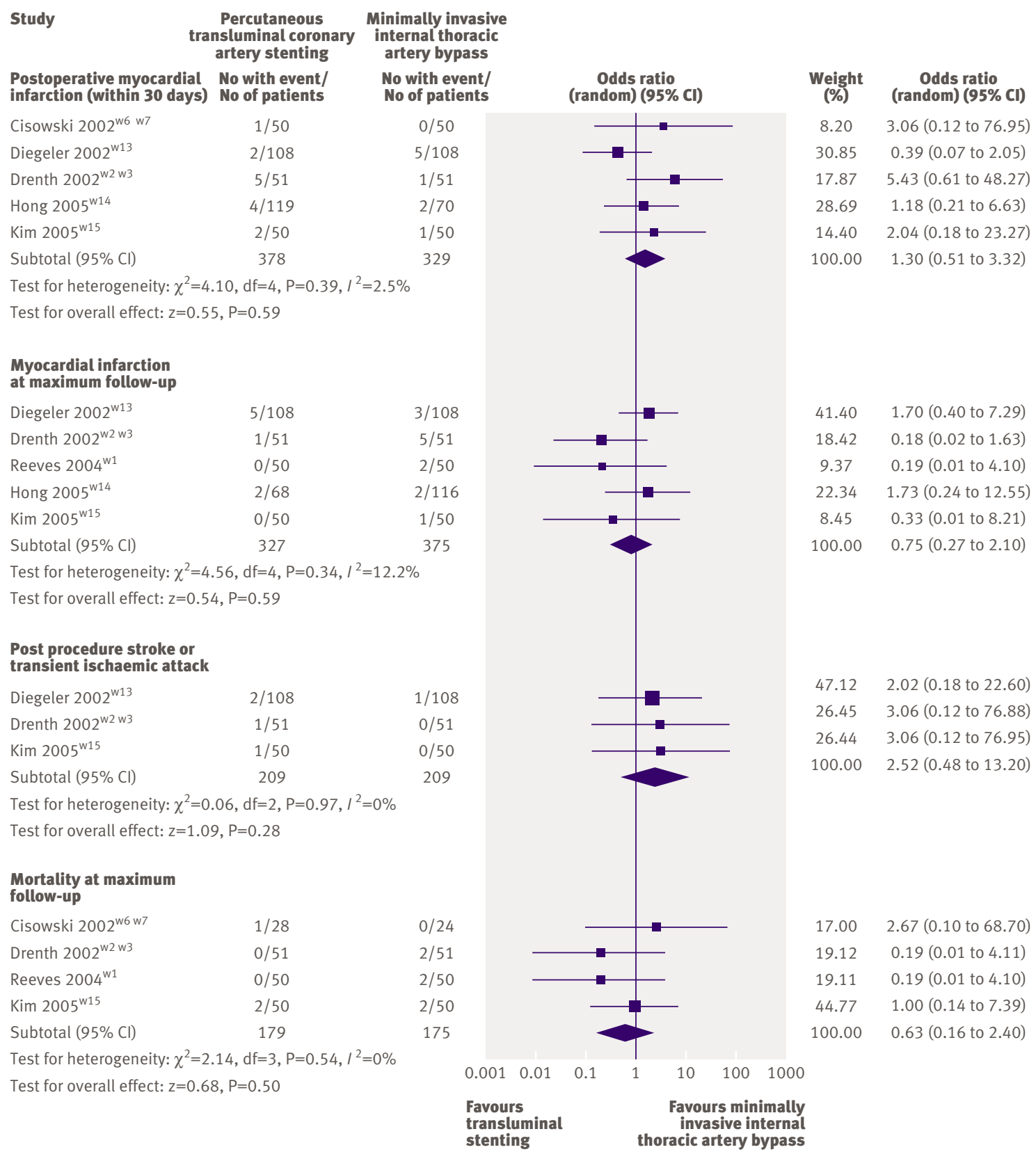

Fig 2 | Forest plot showing results from meta-analysis of randomised trials reporting postoperative myocardial infarction, myocardial infarction at maximum follow-up, mortality at maximum follow-up, and post-procedural stroke or transient ischaemic attack after minimally invasive thoracic artery bypass compared with transluminal stenting

revascularisation, and mortality at maximum followup. The lowest heterogeneity for repeat revascularisation at maximum follow-up was identified when only randomised trials were considered, followed by studies with more than 70 patients in each group. Figure 3 shows a funnel plot of the eight studies reporting this outcome and figure 4 shows a funnel plot for only randomised studies reporting this outcome. In figure 4 the studies are distributed more closely within the $95 \%$ confidence interval axis.

\section{DISCUSSION}

The findings from our meta-analysis of studies comparing minimally invasive direct coronary artery bypass with percutaneous transluminal coronary artery stenting suggest that for isolated lesions of the left anterior descending artery the minimally invasive intervention produces a more definitive revascularisation in the mid-term, with a reduced rate of recurrence of angina, incidence of the composite outcome of major adverse coronary and cerebral events, and need for repeat revascularisation. A possible explanation for this may be that stenting has a greater potential to occlude septal branches and diagonals, affecting interventricular septal blood supply. The primary intervention strategy for this disease should therefore be based more on the quality of the revascularisation than just initial morbidity. 
Table 2 | Results of sensitivity analysis for postoperative complications

\begin{tabular}{|c|c|c|c|c|c|c|}
\hline \multirow[b]{2}{*}{ Variable } & \multicolumn{2}{|c|}{$\begin{array}{c}\text { Postoperative myocardial } \\
\text { infarction }\end{array}$} & \multicolumn{2}{|c|}{ Need for repeat revascularisation } & \multicolumn{2}{|c|}{ Mortality at maximum follow-up } \\
\hline & $\begin{array}{l}\text { Fixed effects } \\
\text { model }\end{array}$ & $\begin{array}{c}\text { Random effects } \\
\text { model }\end{array}$ & $\begin{array}{l}\text { Fixed effects } \\
\text { model }\end{array}$ & $\begin{array}{l}\text { Random effects } \\
\text { model }\end{array}$ & $\begin{array}{l}\text { Fixed effects } \\
\text { model }\end{array}$ & $\begin{array}{c}\text { Random } \\
\text { effects model }\end{array}$ \\
\hline \multicolumn{7}{|l|}{ Overall } \\
\hline Odds ratio $(95 \% \mathrm{Cl})$ & $0.88(0.41$ to 1.88$)$ & 0.91 (0.38 to 2.19) & $\begin{array}{c}3.62(2.38 \text { to } \\
5.51)\end{array}$ & $3.66(2.35$ to 5.41$)$ & $\begin{array}{c}0.77 \text { (0.35 to } \\
1.71)\end{array}$ & $\begin{array}{c}0.83(0.35 \text { to } \\
1.97)\end{array}$ \\
\hline Heterogeneity (P value)* & \multicolumn{2}{|c|}{$6.25(0.40)$} & \multicolumn{2}{|c|}{$3.49(0.84)$} & \multicolumn{2}{|c|}{$2.44(0.66)$} \\
\hline \multicolumn{7}{|l|}{ No of adverse events $†$ : } \\
\hline PTCS & \multicolumn{2}{|c|}{$16 / 1248$} & \multicolumn{2}{|c|}{$185 / 1295$} & \multicolumn{2}{|c|}{$18 / 620$} \\
\hline MIDCAB & \multicolumn{2}{|c|}{$10 / 587$} & \multicolumn{2}{|c|}{$28 / 635$} & \multicolumn{2}{|c|}{$10 / 294$} \\
\hline \multicolumn{7}{|l|}{ Randomised } \\
\hline Odds ratio $(95 \% \mathrm{Cl})$ & $1.36(0.59$ to 3.12$)$ & 1.3 (0.51 to 3.32$)$ & $\begin{array}{l}4.63(2.52 \text { to } \\
8.51)\end{array}$ & $4.55(2.47$ to 8.37$)$ & $\begin{array}{c}0.57 \text { (0.17 to } \\
1.89)\end{array}$ & $\begin{array}{c}0.63(0.16 \text { to } \\
2.40)\end{array}$ \\
\hline Heterogeneity (P value)* & \multicolumn{2}{|c|}{$4.10(0.39)$} & \multicolumn{2}{|c|}{$1.05(0.96)$} & \multicolumn{2}{|c|}{$2.14(0.54)$} \\
\hline \multicolumn{7}{|l|}{ No of adverse eventst: } \\
\hline PTCS & \multicolumn{2}{|c|}{$14 / 378$} & \multicolumn{2}{|c|}{$57 / 425$} & \multicolumn{2}{|c|}{$3 / 179$} \\
\hline MIDCAB & \multicolumn{2}{|c|}{$9 / 329$} & \multicolumn{2}{|c|}{$14 / 377$} & \multicolumn{2}{|c|}{$6 / 175$} \\
\hline \multicolumn{7}{|l|}{ Follow-up >12 months } \\
\hline Odds ratio $(95 \% \mathrm{Cl})$ & $0.89(0.38$ to 2.07$)$ & 0.91 (0.29 to 2.79) & 3.7 (2.42 to 5.68$)$ & 3.65 (2.39 to 5.59$)$ & $\begin{array}{c}0.77 \text { (0.35 to } \\
1.71)\end{array}$ & $\begin{array}{c}0.83(0.35 \text { to } \\
1.99)\end{array}$ \\
\hline Heterogeneity (P value)* & \multicolumn{2}{|c|}{$6.24(0.28)$} & \multicolumn{2}{|c|}{$3.12(0.79)$} & \multicolumn{2}{|c|}{$2.44(0.66)$} \\
\hline \multicolumn{7}{|l|}{ No of adverse eventst: } \\
\hline PTCS & \multicolumn{2}{|c|}{$12 / 1129$} & 182 & $/ 1179$ & & \\
\hline MIDCAB & $8 / 5$ & 517 & & /567 & & \\
\hline$>70$ patients in each grou & & & & & & \\
\hline Odds ratio $(95 \% \mathrm{Cl})$ & $0.59(0.22$ to 1.55$)$ & $0.59(0.21$ to 1.7$)$ & 3.29 (2.08 to 5.2$)$ & $3.24(2.05$ to 5.13$)$ & NA & NA \\
\hline Heterogeneity (P value)* & 2.24 & $(0.52)$ & 2.30 & $(0.51)$ & & \\
\hline No of adverse events†: & & & & & & \\
\hline PTCS & $8 / 1$ & 097 & 162 & /1094 & & \\
\hline MIDCAB & $8 / 4$ & 36 & & /434 & & \\
\hline $\begin{array}{l}\text { PTCS = percutaneous trans } \\
{ }^{*} X^{2} \text { test. } \\
+ \text { Patients may have more }\end{array}$ & $\begin{array}{l}\text { al coronary artery ste } \\
\text { one event. }\end{array}$ & nting; $M I D C A B=$ mini & nally invasive direc & coronary artery bypa & ; $N A=$ not availa & \\
\hline
\end{tabular}

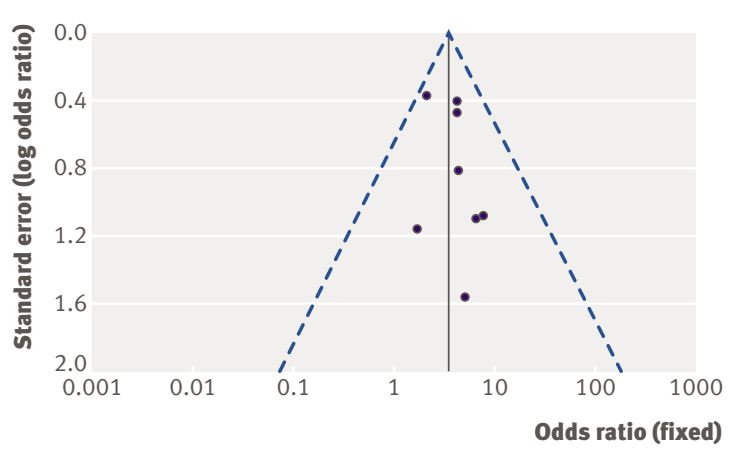

Fig 3 | Scatter plot of studies reporting need for repeat revascularisation at maximum follow-up

Several aspects of the included studies deserve consideration. Firstly, none of the studies matched patients for severity of lesions, which has important implications for the success of transluminal stenting (low, moderate, and high risk). ${ }^{16}$ Patients with tortuous and diffuse coronary lesions are at greater risk of periprocedural complications from transluminal stenting and may benefit even further from minimally invasive internal thoracic artery bypass. Secondly, as with any minimally invasive surgical technique, the effect of the learning curve for minimally invasive internal thoracic artery bypass must be clarified as it will affect patency rates. Thirdly, advances in robotic minimally invasive direct coronary artery bypass mean that the anastomosis itself can be carried out with further minimisation of trauma. ${ }^{6}$ Finally, emergence of new technologies such as drug eluting stents offer the potential to improve the outcome from transluminal stenting, although recent evidence does not show that their use translates to a reduction in total mortality. ${ }^{17}$

\section{Study limitations}

Our meta-analysis has several limitations. Firstly, despite our best efforts to select outcome measures that were as absolute as possible the studies may have had slightly different criteria for defining the outcomes of interest thereby increasing heterogeneity. Secondly, neither the allocation of treatment nor the assessment of outcome was blinded. Thirdly, publication bias needs to be borne in mind, particularly in meta-analytic research based on published studies. Fourthly, although the use of a composite outcome (major adverse coronary and cerebral events) is not as robust as reporting its individual components, we included it in this analysis because it is extensively reported in the literature. Finally, the studies varied in inclusion 


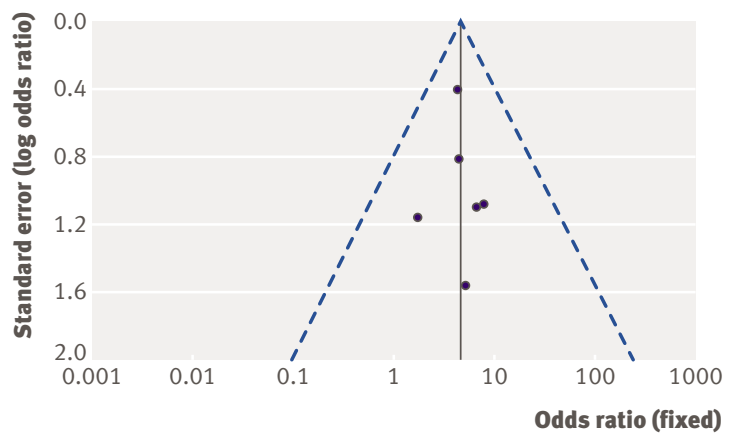

Fig $4 \mid$ Scatter plot of randomised studies reporting need for repeat revascularisation at maximum follow-up

\section{WHAT IS ALREADY KNOWN ON THIS TOPIC}

Surgical bypass may offer a more favourable long term outcome for multiple vessel coronary disease compared with percutaneous interventions

Debate centres on what primary revascularisation strategy is best for patients with isolated lesions of the left anterior descending artery

\section{WHAT THIS STUDY ADDS}

For isolated disease of the left anterior descending artery disease, minimally invasive left internal thoracic artery bypass results in fewer mid-term complications than transluminal stenting approach, which we have undertaken to compare the long term cost effectiveness and effect on quality of life of the two interventions for this patient group. ${ }^{19}$

Contributors: $\mathrm{OA}$ was responsible for the study design, statistical analysis, data interpretation, manuscript drafting and revision for important intellectual content. CR, SSP, and CJ were responsible for the collection, extraction, analysis, and interpretation of the data. SM was responsible for manuscript design and statistical analysis. AD was responsible for providing important intellectual content throughout the manuscript's production and for approval of the final version. TA is the guarantor. His involvement was critical to every phase of this work and he had access to the data and controlled the decision to publish. Funding: This study was undertaken as part of ongoing research at the Department of Biosurgery and Surgical Technology, Imperial College London, and did not receive separate funding

Competing interests: None declared.

Ethical approval: Not required.

1 Poyen V, Silvestri M, Labrunie P, Valeix B. Indications of coronary angioplasty and stenting in 2003: what is left to surgery? J Cardiovasc Surg (Torino) 2003;44:307-12.

2 Opie LH, Commerford PJ, Gersh BJ. Controversies in stable coronary artery disease. Lancet 2006;367:69-78.

3 Meads C, Cummins C, Jolly K, Stevens A, Burls A, Hyde C. Coronary artery stents in the treatment of ischaemic heart disease: a rapid and systematic review. Health Technol Assess 2000;4:1-153.

4 Versaci F, Gaspardone A, Tomai F, Proietti I, Ghini AS, Altamura L, et al. A comparison of coronary artery stenting with angioplasty for isolated stenosis of the proximal left anterior descending coronary artery: five year clinical follow up. Heart 2004;90:672-5.

5 Niinami H, Takeuchi Y, Ichikawa S, Suda Y. Partial median sternotomy as a minimal access for off-pump coronary artery bypass grafting: feasibility of the lower-end sternal splitting approach. Ann Thorac Surg 2001;72(3):S1041-5.

6 Casula R, Athanasiou T, Foale R. Recent advances in minimal-access cardiac surgery using robotic-enhanced surgical systems. Expert Rev Cardiovasc Ther 2004;2:589-600.

7 Yock CA, Boothroyd DB, Owens DK, Garber AM, Hlatky MA. Costeffectiveness of bypass surgery versus stenting in patients with multivessel coronary artery disease. Am J Med 2003;115:382-9.

8 Boodhwani M, Rubens FD, Sellke FW, Mesana TG, Ruel M. Mortality and myocardial infarction following surgical versus percutaneous revascularization of isolated left anterior descending artery disease: a meta-analysis. Eur J Cardiothorac Surg 2006;29:65-70.

9 Clarke M, Oxman AD, eds. Cochrane reviewer's handbook 4.1.3 [updated June 2001]. In: The Cochrane Library, Issue 3: Oxford: Update Software, 2001.

10 Moher D, Cook DJ, Eastwood S, Olkin I, Rennie D, Stroup DF. Improving the quality of reports of meta-analyses of randomised controlled trials: the QUOROM statement. Onkologie 2000;23:597-602.

11 Yusuf S, Peto R, Lewis J, Collins R, Sleight P. Beta blockade during and after myocardial infarction: an overview of the randomized trials. Prog Cardiovasc Dis 1985;27:335-71.

12 Mantel N, Haenszel W. Statistical aspects of the analysis of data from retrospective studies of disease. / Natl Cancer Inst 1959;22:719-48.

13 Egger M, Davey Smith G, Schneider M, Minder C. Bias in metaanalysis detected by a simple, graphical test. BMJ 1997;315:629-34.

14 DerSimonian R, Laird N. Meta-analysis in clinical trials. Control Clin Trials 1986;7:177-88.

15 Egger M, Smith GD. Misleading meta-analysis. BMJ 1995;311:753-4

16 Smith SC Jr, Dove JT, Jacobs AK, Kennedy JW, Kereiakes D, Kern MJ, et al. ACC/AHA guidelines for percutaneous coronary intervention (revision of the 1993 PTCA guidelines)—executive summary: a report of the American College of Cardiology/American Heart Association task force on practice guidelines (committee to revise the 1993 guidelines for percutaneous transluminal coronary angioplasty) endorsed by the Society for Cardiac Angiography and Interventions. Circulation 2001;103(24):3019-41.

17 Nordmann AJ, Briel M, Bucher HC. Mortality in randomized controlled trials comparing drug-eluting vs. bare metal stents in coronary artery disease: a meta-analysis. Eur Heart J 2006;27(23):2784-814.

18 Ioannidis JP, Cappelleri JC, Lau J. Issues in comparisons between meta-analyses and large trials. JAMA 1998;279(14):1089-93.

19 Rao C, Aziz O, Panesar SS, Jones C, Morris S, Darzi A, et al. Cost effectiveness analysis of minimally invasive left internal thoracic artery bypass compared with percutaneous revascularisation for isolated lesions of the left anterior descending artery. BMJ 2007; doi $=10.1136 / \mathrm{bmj} .39112 .480023 . \mathrm{BE}$.

Accepted: 5 January 2007 quality of life of minimally invasive internal thoracic artery bypass compared with transluminal stenting. To do this we propose the use of an evidence synthesis 